\title{
OPEN Use of different RT-QuIC substrates for detecting CWD prions in the brain of Norwegian cervids
}

\author{
Edoardo Bistaffa ${ }^{1,4}$, Tram Thu Vuong ${ }^{2,4}$, Federico Angelo Cazzaniga ${ }^{1}$, Linh Tran ${ }^{2}$, \\ Giulia Salzano ${ }^{3}$, Giuseppe Legname $\mathbb{1}^{3}$, Giorgio Giaccone ${ }^{1}$, Sylvie L. Benestad ${ }^{2}$ \& \\ Fabio Moda $\mathbb{( i D}^{1 *}$
}

Chronic wasting disease (CWD) is a highly contagious prion disease affecting captive and free-ranging cervid populations. CWD has been detected in United States, Canada, South Korea and, most recently, in Europe (Norway, Finland and Sweden). Animals with CWD release infectious prions in the environment through saliva, urine and feces sustaining disease spreading between cervids but also potentially to other non-cervids ruminants (e.g. sheep, goats and cattle). In the light of these considerations and due to CWD unknown zoonotic potential, it is of utmost importance to follow specific surveillance programs useful to minimize disease spreading and transmission. The European community has already in place specific surveillance measures, but the traditional diagnostic tests performed on nervous or lymphoid tissues lack sensitivity. We have optimized a Real-Time QuakingInduced Conversion (RT-QuIC) assay for detecting CWD prions with high sensitivity and specificity to try to overcome this problem. In this work, we show that bank vole prion protein $(\operatorname{PrP})$ is an excellent substrate for RT-QuIC reactions, enabling the detection of trace-amounts of CWD prions, regardless of prion strain and cervid species. Beside supporting the traditional diagnostic tests, this technology could be exploited for detecting prions in peripheral tissues from live animals, possibly even at preclinical stages of the disease.

Chronic Wasting Disease (CWD) is a prion disease, a neurodegenerative disorder that affects cervid populations. It was first identified in 1967 in a captive mule deer from Colorado. CWD was then diagnosed across a wide area of North America ${ }^{1}$ where it is spreading extensively. It has also been reported in South Korea, as a consequence of infected animals imported from Canada ${ }^{2}$ and has most recently been reported in Europe ${ }^{3}$ (Norway, Finland and Sweden ${ }^{4,5}$ ). To date, CWD has been identified in mule deer (Odocoileus hemionus) ${ }^{6}$, black-tailed deer (Odocoileus hemionus), white-tailed deer (Odocoileus virginianus) ${ }^{7}$, elk (Cervus canadensis) ${ }^{6,8}$ moose (Alces alces) ${ }^{9}$, reindeer (Rangifer tarandus tarandus) and red deer (Cervus elaphus) $)^{2,10-12}$.

As in other prion diseases, the causative agent is considered to be an abnormally folded isoform of the prion protein $\left(\mathrm{PrP}^{\mathrm{C}}\right)$, named prion or $\mathrm{PrP}^{\mathrm{Sc13}}$, which accumulates mostly in the central nervous system $(\mathrm{CNS}) . \mathrm{PrP}^{\mathrm{C}}$ plays important roles in several physiological processes and is evolutionarily conserved amongst different mammalian species ${ }^{3,6,14-19}$. Misfolded $\mathrm{PrP}^{\mathrm{Sc}}$ propagates through conformational templating where $\operatorname{PrP}^{\mathrm{C}}$ is converted into $\mathrm{PrP}^{\mathrm{Sc}}$ thus acquiring infectious features and sustaining disease $\mathrm{e}^{13,20}$.

Horizontal transmission of CWD is highly efficient, through both animal-to-animal contact and exposure to environments contaminated with prion infected material (e.g. excreta, placenta or carcasses) $)^{21-24}$. Polymorphisms in the PrP gene (Prnp) are known to affect (i) animal susceptibility to CWD, (ii) transmission efficiency between species, (iii) clinical and (iv) neuropathological features of the disease ${ }^{25-28}$. For instance, deer $\operatorname{PrP}^{\mathrm{C}}$ is characterized by having a glycine $(\mathrm{G})$ or serine $(\mathrm{S})$ at codon 96 of $\operatorname{Prn} p^{29,30}$; Moose $\operatorname{PrP}^{\mathrm{C}}$ contains either lysine (K) or glutamine (Q) at position $109^{31}$; Elk $\operatorname{PrP}^{\mathrm{C}}$ has either methionine (M) or leucine (L) at position $132^{26}$; Reindeer $\mathrm{PrP}^{\mathrm{C}}$ has aspartic acid (D) or asparagine $(\mathrm{N})$ at residue $176^{31}$; Mule deer $\operatorname{PrP}^{\mathrm{C}}$ contains either serine (S) or phenylalanine $(\mathrm{F})$ at position $225^{32}$ while Whitetail deer is characterized by having alanine $(\mathrm{A})$ or glycine $(\mathrm{G})$ at position 116 and glutamine $(\mathrm{Q})$ or lysine $(\mathrm{K})$ at position $226^{28}$. These amino acids determine important variability

${ }^{1}$ Fondazione IRCCS Istituto Neurologico Carlo Besta, Division of Neurology 5 and Neuropathology, Milano, Italy. ${ }^{2}$ Norwegian Veterinary Institute, Oslo, Norway. ${ }^{3}$ Scuola Internazionale Superiore di Studi Avanzati (SISSA), Laboratory of Prion Biology, Department of Neuroscience, Trieste, Italy. ${ }^{4}$ These authors contributed equally: Edoardo Bistaffa and Tram Thu Vuong. *email: fabio.moda@istituto-besta.it 
in disease phenotypes or susceptibility to CWD infection. For example, the expression of L at position 132 of elk PrP appears to confer, at least partially, resistance to CWD when compared to the more prevalent $132 \mathrm{M}$ allele ${ }^{33}$. Similarly, the expression of $S$ at position 96 of deer PrP is linked to reduced incidence of CWD ${ }^{34}$.

Thus, other than dictating CWD susceptibility, PrP polymorphisms seem to play an important role in prion strains selection ${ }^{35-37}$. Strains are extremely relevant in prion diseases since they determine variability in clinical phenotype of the disease, and influence the characteristics of $\mathrm{PrP}^{\mathrm{Sc}}$ that acquires distinct biochemical properties (e.g., electrophoretic mobility in Western blot (WB) and analysis of glycoforms ratio after treatment with proteinase K) and differentially accumulates in specific brain areas ${ }^{38-43}$. Differences in strain behavior and features are known to rely on different abnormal conformations that could be acquired by $\operatorname{PrP}^{\mathrm{Sc}}$. Strains conformational mutations can be further promoted during CWD transmission between species where $\mathrm{PrP}^{\mathrm{Sc}}$ is subjected to important processes of selection and adaptation in the new host ${ }^{36,44-46}$.

Definite CWD diagnosis relies on post-mortem detection of $\mathrm{PrP}^{S c}$ in the brainstem and the head lymph nodes $^{4-49}$ using rapid tests (enzyme-linked immunosorbent assays (ELISA), WB and/or immunohistochemistry $(\mathrm{IHC}))^{50-52}$. PrP $\mathrm{P}^{\mathrm{Sc}}$ can be detected in peripheral lymphoid tissues (especially those associated with the alimentary canal) of most CWD affected animals, like in sheep affected with classical scrapie, before it can be detected in the brain ${ }^{48,53,54}$. For instance, IHC analyses of the palatine tonsils and recto-anal mucosa-associated lymphoid tissues (RAMALT) are used for an ante-mortem diagnosis of CWD in deer ${ }^{49,55-57}$. Nevertheless, in some CWD affected elks, while $\mathrm{PrP}^{\mathrm{Sc}}$ is detected in the brain, the presence of $\mathrm{PrP}^{\mathrm{Sc}}$ in the lymphoid tissues can be minimal or undetectable, which represents an important limitation for the ante-mortem diagnosis ${ }^{58,59}$. Similarly, Norwegian moose and red deer show $\mathrm{PrP}^{\mathrm{Sc}}$ in the brain but $\mathrm{PrP}^{\mathrm{Sc}}$ was not detected in lymphoid tissues ${ }^{3,9,60}$. Reindeer in Norway, conversely, have detectable lymphoid $\mathrm{PrP}^{\mathrm{Sc}}$ accumulation even in animals where no $\mathrm{PrP}^{\mathrm{Sc}}$ is detected in the $\mathrm{CNS}^{3}$.

However, at early stages of the disease, also the amount of $\mathrm{PrP}^{\mathrm{Sc}}$ in peripheral lymph nodes is lower than the detection threshold of traditional diagnostic techniques ${ }^{61}$. In this case, the most reliable way to detect low titer of infectious prions is therefore by animal bioassay. Even though these experiments remain the gold standard for measuring low amounts of infectivity, they are time consuming, expensive and can therefore not be used as screening tests ${ }^{62-65}$.

Thanks to the recent development of in vitro cell-free amplification techniques, including the Protein Misfolding Cyclic Amplification (PMCA) and the Real Time Quaking Induced Conversion (RT-QuIC) assays, it is possible to detect trace-amounts of CWD prions in different peripheral tissues and biological fluids ${ }^{66}$. In particular, PMCA showed the presence of $\mathrm{PrP}^{\mathrm{Sc}}$ in muscles ${ }^{67}$, feces ${ }^{68,69}$, saliva ${ }^{70}$, cerebrospinal fluid $(\mathrm{CSF})^{71}$ and even the blood of animals at different stages of CWD infection ${ }^{72,73}$. Unfortunately, there is no universal PMCA substrate for amplifying CWD from different species. This technique, therefore would seem not to be the method of choice when analyzing samples that are collected in the field (feces or saliva) from species with unknown origin. In RT-QuIC, through alternate cycles of incubation and shaking, prions force the substrate of reaction (recombinant $\operatorname{PrP}$ ) to adopt $\beta$-sheet structures ${ }^{74}$. These abnormally folded PrP proteins aggregate and form amyloid fibrils whose growth is monitored with Thioflavin-T (ThT) fluorescent dye. The assay has been used extensively for detecting CWD prions in nasal swabs ${ }^{75}$, lymphoid tissues ${ }^{76}, \mathrm{CSF}^{71}$, blood $^{77}$, saliva ${ }^{78,79}$, urine ${ }^{80}$ and feces $^{81,82}$ of animals at clinical and, sometimes, preclinical stages of disease. The presence of CWD prions in the saliva, urine and feces of affected animals suggests that substantial environmental contamination can occur during the entire course of the disease, especially considering that sialorrhea and polyuria are common in diseased animals ${ }^{83-87}$. Moreover, prions can persist in the environment for many years and thus represent a serious risk of future contamination upon restocking of CWD-exposed areas ${ }^{1,88-93}$.

For this reason, RT-QuIC due to its high sensitivity and high-throughput potential can have useful applications for ante-mortem identification of CWD infected animals. However, the technique detects different prion strains or strains belonging to different species with variable efficiency. To date, most of the RT-QuIC experiments described in the literature have been performed using primarily Syrian hamster or deer $\operatorname{PrP}$ as substrate of reaction (see Table 1). In the present study, RT-QuIC analyses were performed on serial dilutions of brain homogenates collected from both healthy and CWD-affected Norwegian moose, reindeer and red deer, using different substrates. We evaluated the ability of truncated PrP from Syrian hamster, bank vole, deer, reindeer and elk to detect brain derived $\mathrm{PrP}^{\mathrm{Sc}}$ regardless of animal species or prion strain. This is also the first time where RT-QuIC has been used to analyze samples from CWD affected Norwegian reindeer.

Our results indicate that the use of bank vole PrP provided efficient prion detection in all CWD affected animals, even in the instances where traditional diagnostic methods (WB, IHC or ELISA) failed to demonstrate the presence of $\mathrm{PrP}^{\mathrm{Sc}}$. This optimized RT-QuIC assay could therefore be used as a screening test for CWD detection. It could also be a useful research tool for analyzing other tissues with low levels of $\operatorname{Pr} \mathrm{P}^{\mathrm{Sc}}$ like peripheral tissues from live animals or excreta (such as urine, saliva and blood) that can be collected through non-invasive procedures. Moreover, although there are no documented cases of natural interspecies transmission of CWD to non-cervid animals, many livestock (especially sheep and goats) which share their habitat with diseased cervids will be exposed to prions and could potentially be infected. Although there is a so-called "species barrier", which is related to differences in PrP sequences between donor and acceptor animals that can limit the efficiency of prion transmission between species (spillover phenomenon that occur for instance from cervids to small ruminants), the potential risk of breaking such barrier cannot be excluded. For instance, CWD transmission to other species (especially human) cannot be completely ruled out at present ${ }^{64,94,95}$. For this reason, identifying preclinical CWD affected animals is of fundamental importance for minimizing horizontal disease transmission. 


\begin{tabular}{|c|c|c|c|c|c|}
\hline Species & Prion & Tissue analyzed & Substrate & Year & References \\
\hline Deer & CWD & Brain & Deer PrP (24-234) & 2010 & 130 \\
\hline Deer & CWD & Brain, urine and feces & Deer PrP (24-234) & 2013 & 80 \\
\hline Deer & CWD & Saliva & Syrian hamster $\operatorname{PrP}(90-231)$ & 2013 & 79 \\
\hline Deer & CWD & Blood & Syrian hamster $\operatorname{PrP}(90-231)$ & 2013 & 77 \\
\hline Deer & CWD & CSF & Syrian hamster PrP (90-231) & 2013 & 71 \\
\hline Deer & CWD & Retropharyngeal lymph node & Syrian hamster PrP (90-231) & 2014 & 131 \\
\hline Deer & CWD & Brain, saliva & Syrian hamster $\operatorname{PrP}(90-231)$ & 2015 & 132 \\
\hline $\begin{array}{l}\text { Deer } \\
\text { Elk }\end{array}$ & CWD & Brain & Bank vole (23-230) & 2015 & 100 \\
\hline Deer & CWD & Saliva, urine & Syrian hamster PrP (90-231) & 2015 & 78 \\
\hline Deer & CWD & Brain & Deer PrP $(23-231)$ & 2015 & 124 \\
\hline Deer & CWD & RAMALT, nasal brush & Syrian hamster PrP (90-231) & 2016 & 75 \\
\hline Elk & CWD & RAMALT, nasal brush & Syrian hamster PrP (90-231) & 2016 & 76 \\
\hline Deer & CWD & Feces & Syrian hamster $\operatorname{PrP}(90-231)$ & 2016 & 69 \\
\hline Deer & CWD & Brain, lymphoid tissues & Syrian hamster $\operatorname{PrP}(90-231)$ & 2017 & 133 \\
\hline Deer & CWD & $\begin{array}{l}\text { Ovary tissue, uterine tissue, } \\
\text { placentome, amniotic and } \\
\text { allantoic fluids }\end{array}$ & Syrian hamster $\operatorname{PrP}(90-231)$ & 2017 & 134 \\
\hline Deer & CWD & Brain & Deer PrP (24-234) & 2017 & 135 \\
\hline Deer & CWD & $\begin{array}{l}\text { Gastrointestinal tissues (e.g. } \\
\text { omasum, abomasum, colon, cecum) } \\
\text { and lymphoid tissues (e.g. spleen, } \\
\text { tonsils) }\end{array}$ & Syrian hamster $\operatorname{PrP}(90-231)$ & 2017 & 136 \\
\hline Elk & CWD & Feces & Syrian hamster $\operatorname{PrP}(90-231)$ & 2017 & 82 \\
\hline Elk & CWD & RAMALT & Syrian hamster PrP (90-231) & 2017 & 137 \\
\hline Deer & CWD & Saliva & Syrian hamster $\operatorname{PrP}(90-231)$ & 2017 & 138 \\
\hline \multirow{5}{*}{$\begin{array}{l}\text { Deer } \\
\text { Elk }\end{array}$} & \multirow{5}{*}{ CWD } & \multirow{5}{*}{ RAMALT } & White-tailed deer PrP (25-232) & \multirow{5}{*}{2017} & \multirow{5}{*}{139} \\
\hline & & & Mule deer $\operatorname{PrP}(25-232)$ & & \\
\hline & & & Fallow deer $\operatorname{PrP}(25-232)$ & & \\
\hline & & & Elk PrP (25-232) & & \\
\hline & & & Reindeer PrP (25-232) & & \\
\hline Elk & CWD & Blood, rectal biopsy & Syrian hamster $\operatorname{PrP}(90-231)$ & 2018 & 140 \\
\hline $\begin{array}{l}\text { Deer } \\
\text { Elk }\end{array}$ & CWD & Retropharyngeal lymph node, brain & Syrian hamster $\operatorname{PrP}(90-231)$ & 2018 & 60 \\
\hline Deer & CWD & Saliva & Syrian hamster $\operatorname{PrP}(90-231)$ & 2018 & 70 \\
\hline Elk & CWD & Brain & Elk PrP (23-231) & 2018 & 141 \\
\hline Elk & CWD & Brain & Syrian hamster $\operatorname{PrP}(90-231)$ & 2019 & 4 \\
\hline Deer & CWD & Brain & Syrian hamster $\operatorname{PrP}(90-231)$ & 2019 & 142 \\
\hline Deer & CWD & Brain, eyelids & Syrian hamster $\operatorname{PrP}(90-231)$ & 2019 & 143 \\
\hline
\end{tabular}

Table 1. Summary of RT-QuIC substrates (PrP) used to analyze different tissues of CWD affected cervid species.

\section{Results}

$\mathrm{TeSeE}^{\mathrm{TM}} \mathrm{WB}$ analysis detects prions in brain or lymph nodes of CWD affected animals. The CWD affected animals used in this study were identified through the Norwegian surveillance program for CWD that has been started in 2016 . These animals were firstly diagnosed by TeSeE ${ }^{\mathrm{TM}}$ ELISA test and then confirmed by WB analysis (diagnostic statuses are summarized in Table 2). To verify the presence of different distribution patterns of CWD prions in both brain and lymph nodes WB analyses were finally performed. Proteinase $\mathrm{K}$ resistant $\operatorname{PrP}\left(\mathrm{PrP}^{\mathrm{res}}\right)$ was found in the samples from all the CWD affected moose (Mo1, Mo2 and Mo3) and red deer (Rd1), while PrPres was detected only in 3 out of 7 brain samples of CWD affected reindeer (Fig. 1a). In contrast, PrPres was not found in the lymph nodes of CWD affected moose and red deer but always detected in lymph nodes of the CWD affected reindeer (Re1-Re7) (Fig. 1b). PrPres was not detected in any of the samples (brain or lymph node) collected from healthy animals.

RT-QuIC analysis with bank vole PrP enables efficient prion detection in brain samples from cervids where PrP ${ }^{\mathrm{SC}}$ was biochemically detected. With the aim of evaluating the efficiency of different substrates in detecting CWD prions in different cervid species, RT-QuIC experiments were performed using recombinant $\operatorname{PrP}$ proteins with amino acidic sequences belonging to the following animal species: Syrian hamster, bank vole (109 M), deer (96 G), reindeer (176D) and elk (132 M) (Fig. 2). According to the most recent publications (see Table 1), we decided to use truncated proteins since the C-terminal protein domain allows prion detection with high sensitivity and specificity ${ }^{96,97}$. Evaluation of the overall RT-QuIC performance was based on brain samples collected from CWD affected animals where $\operatorname{PrP}^{\mathrm{Sc}}$ was detected by means of $\mathrm{TeSe}^{\mathrm{TM}}$ ELISA and 


\begin{tabular}{|c|c|c|c|c|c|c|c|}
\hline \multirow[b]{2}{*}{ Species } & \multirow[b]{2}{*}{ Sample ID } & \multirow[b]{2}{*}{ Status } & \multirow{2}{*}{$\begin{array}{l}\text { Geographic } \\
\text { origin }\end{array}$} & \multirow[b]{2}{*}{ Sex } & \multirow[b]{2}{*}{ Age(y) } & \multicolumn{2}{|c|}{ PrPres detection } \\
\hline & & & & & & Brain & LN \\
\hline \multirow{5}{*}{ Alces alces } & Mol & CWD & Lierne & Female & 13 & + & - \\
\hline & Mo2 & CWD & Selbu & Female & 13 & + & - \\
\hline & Mo3 & CWD & Selbu & Female & 14 & + & - \\
\hline & Mo4 & Healthy & Råde & Unknown & $>1$ & - & - \\
\hline & Mo5 & Healthy & Voss & Male & $>1$ & - & - \\
\hline \multirow{3}{*}{ Cervus elaphus } & Rd1 & CWD & Gjemnes & Female & 16 & + & - \\
\hline & $\mathrm{Rd} 2$ & Healthy & Eid & Female & $>1$ & - & - \\
\hline & Rd3 & Healthy & Årdal & Male & $>1$ & - & - \\
\hline \multirow{9}{*}{$\begin{array}{l}\text { Rangifer tarandus } \\
\text { tarandus }\end{array}$} & Re1 & CWD & Nordfjella & Male & $>1$ & + & + \\
\hline & Re2 & CWD & Nordfjella & Female & $>1$ & + & + \\
\hline & Re3 & CWD & Nordfjella & Male & $>1$ & + & + \\
\hline & Re4 & CWD & Nordfjella & Female & $>1$ & - & + \\
\hline & Re5 & CWD & Nordfjella & Male & 1.5 & - & + \\
\hline & Re6 & CWD & Nordfjella & Female & $>1$ & - & + \\
\hline & $\operatorname{Re} 7$ & CWD & Nordfjella & Male & 8 & - & + \\
\hline & Re8 & Healthy & Lom & Male & $>1$ & - & - \\
\hline & Re9 & Healthy & Lom & Female & $>1$ & - & - \\
\hline
\end{tabular}

Table 2. Demographic information and $\mathrm{TeSeE}^{\mathrm{TM}} \mathrm{WB}$ results of the Norwegian animals included in this study.

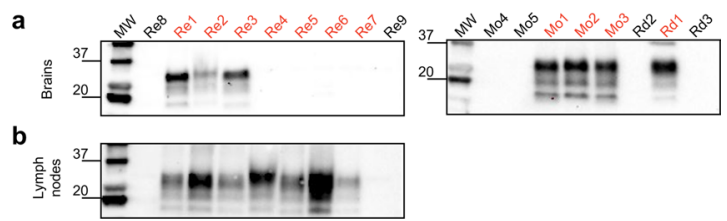

Figure 1. TeSeE ${ }^{\mathrm{TM}} \mathrm{WB}$ results of brain and lymph nodes collected from the healthy (black) and CWD affected (red) animals included in the study. (a) PrPres was detected in all brain homogenates of CWD affected moose (Mo1, Mo2, Mo3), red deer (Rd1) and 3 brain homogenates (out of 7) of CWD affected reindeer. Notably, no $\mathrm{PrP}^{\mathrm{res}}$ was detected in the brains of CWD affected reindeer 4, 5, 6, and 7; (b) $\mathrm{PrP}^{\text {res }}$ was however detected in the lymph nodes of all the CWD affected reindeer. PrPres was not found in brain and lymph nodes of healthy animals. Numbers on the left of the Western blots indicate molecular weights $(\mathrm{kDa})$.

WB. Brain homogenates of Rd1, Mo1, Mo2, Mo3, Re1, Re2 and Re3 were diluted from $10^{-5}$ to $10^{-7}$ and subjected to RT-QuIC analysis. Brain samples of healthy animals (Rd2, Rd3, Mo4, Mo5, Re8 and Re9) were used as controls.

Regardless of the animal species or brain dilution, bank vole PrP enabled $\mathrm{PrP}^{\mathrm{Sc}}$ detection with a higher sensitivity and specificity compared to the other tested substrates (Fig. 3a). Particularly, all CWD affected animals' samples induced RT-QuIC seeding activity within 10 hours while those of healthy controls did not. The reaction was stopped at 16 hours because at this point negative controls started to induce unspecific seeding activity.

Compared to the bank vole PrP, Syrian hamster PrP substrate did not detect all CWD affected animals' samples and the sensitivity decreased at higher dilutions. In particular, one (Re2), two (Re1 and Re2) or three (Re1, Re2 and Rd1) CWD affected animals' samples were not detected at $10^{-5}, 10^{-6}$ or $10^{-7}$ dilutions, respectively (Fig. 3b). Notably, this substrate hardly detected Norwegian reindeer CWD prions compared to the moose and red deer ones. The reaction was stopped at 53 hours and none of the negative controls induced unspecific reaction. We analyzed whether the prion protein sequence homology between CWD prions and substrate could increase the power of discrimination between prion affected and healthy animals. We then analyzed the samples using $\operatorname{PrP}$ substrates with amino acid sequences of deer, reindeer and elk. Surprisingly, while deer PrP (Fig. 3c) was still able to detect CWD affected animals' samples with sensitivity and specificity quite comparable to that of Syrian hamster PrP, reindeer (Fig. 3d) and elk PrP (Fig. 3e) were characterized by a very rapid aggregation in both the positive and the negative samples. Even with a time threshold of 3 hours, we could not clearly discriminate between CWD affected animals and healthy controls. Thus, PrP substrates with cervid sequences appear to be less efficient in detecting CWD prions than those with bank vole and Syrian hamster sequences.

Two brain samples from CWD affected white-tailed deer (WTd) from North America were included in the RT-QuIC analysis to verify whether the overall performance of the assay could have been influenced by the origin of the CWD prions (Norway vs North America). The two isolates were provided to the Norwegian Veterinary Institute in Oslo in 2006 as part of a ring trial (courtesy of Aru Balachandran, Canadian Food Inspection Agency, Alberta, Canada). In this case, their seeding activities were similar to that of Norwegian CWD affected deer, in terms of lag phase and fluorescence intensity (Fig. 4 and see Supplementary Fig. S1). 
Deer PrP

Reindeer PrP

Elk PrP

Syrian Hamster PrP

Bank vole PrP

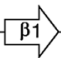

94- G-QGGTHSQWNKPSKPKTNMKHVAGAAAAGAVVGGLGGYMLGSAMSRPLIHFGNDYEDRYYRENMYRYPNQ -163

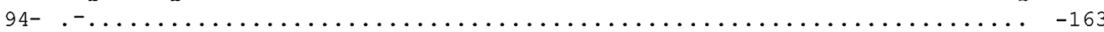

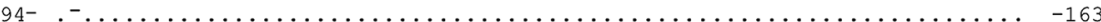

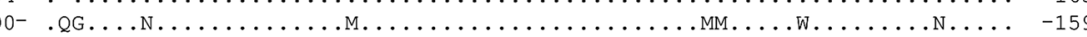

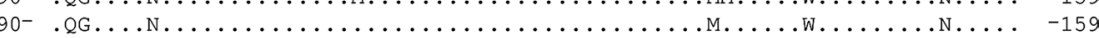

Deer PrP
Reindeer PrP
Elk PrP
Syrian Hamster PrP
Bank vole PrP $\beta 2$

164- VYYRPVDQYNNQNTFVHDCVNITVKQHTVTTTTKGENFTETDIKMMERVVEQMCITQYQRESQAYYQRGAS -234

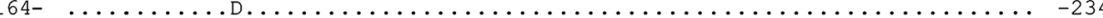

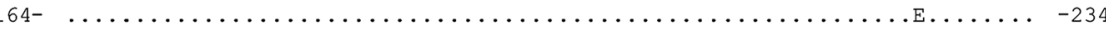

$160-\ldots \ldots \ldots \ldots$. . . . . . . . . . . . . . . . . . . . . . . . . .

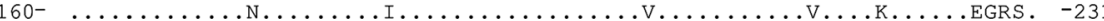

Figure 2. Amino acid sequences of recombinant PrP proteins used for RT-QuIC experiments. The amino acid sequence of deer PrP was used as reference for aligning the sequences of reindeer, elk, Syrian hamster and bank vole PrP. Arrows and rectangles indicate beta-sheets $(\beta 1$ and $\beta 2)$ and alpha helix $(\alpha 1, \alpha 2$ and $\alpha 3)$ secondary structures, respectively.

RT-QuIC analysis with bank vole PrP enables efficient prion detection in reindeer brain samples where $\mathrm{PrP}^{\mathrm{Sc}}$ was not biochemically detected. Finally, we have analyzed samples collected from CWD affected reindeer (Re4, Re5, Re6, Re7) where $\operatorname{Pr}^{P^{s c}}$ had only been detected in the lymph nodes and not the brain with TeSeE ${ }^{\mathrm{TM}}$ ELISA and WB. We decided not to perform serial dilutions given the lack of WB signal in the brain samples and chose a dilution of $10^{-5}$. As previously observed, the bank vole $\mathrm{PrP}$ was the most efficient at detecting prions in all the CWD affected reindeer (Fig. 5a). The Syrian hamster PrP did not detect 2 out of 4 CWD samples (Re6 and Re7) (Fig. 5b); whilst deer (Fig. 5c) and reindeer PrP (Fig. 5d) did not detect 3 out of the 4 CWD samples (Re4, Re6, Re7 and Re4, Re5, Re6, respectively). Elk PrP did not detect any of them (Fig. 5e).

\section{Discussion}

First discovered in deer in Colorado many decades ago, CWD rapidly spread to many other American states ${ }^{98}$ and Canada $^{10}$. In April 2016, the disease was diagnosed in a Norwegian reindeer from the Nordfjella area ${ }^{3}$. This was the first case of CWD in Europe, and the first reindeer reported with naturally occurring CWD. This disease is contagious within cervid populations and can efficiently transmit directly between animals or through the environment. Healthy animals can be infected after close contact with saliva, urine and feces of affected ones (direct horizontal transmission) or after being exposed to environments contaminated with excreta or carcasses of diseased animals (indirect horizontal transmission). Prions persist in the environment for long time and contribute significantly to disease spreading.

In Europe surveillance programs are aimed at detecting the presence of CWD in wild and farmed cervids. The validated and approved diagnostic tests require animals to be sacrificed for sampling the CNS (e.g. brainstem) and/or lymphoid tissue for ELISA, WB and IHC based analyses ${ }^{61}$. Although these tests reach high levels of diagnostic accuracy for $\mathrm{CWD}, \mathrm{PrP}^{\mathrm{Sc}}$ accumulation in brain and lymphoid tissues can be lower than the detection threshold of the tests, especially in the early stages of disease. In addition, different CWD prion strains can affect test performance, as in the case of Nor98/atypical scrapie ${ }^{99}$.

In this work we evaluated the efficiency of the highly sensitive RT-QuIC assay in detecting low amounts of CWD prion in different Norwegian cervid species. Our aim was to set up optimal conditions for $\mathrm{PrP}^{\mathrm{Sc}}$ detection, regardless of prion strains and animal species. For this reason, brain homogenates of CWD affected moose, red deer and reindeer were serially diluted and subjected to RT-QuIC analysis performed using Syrian hamster, bank vole, deer, reindeer and elk $\mathrm{PrP}$ as reaction's substrates.

Our results indicated that the bank vole PrP enabled CWD prion detection in every brain dilution of all cervid species, especially in reindeer where $\mathrm{PrP}^{\mathrm{Sc}}$ detection was more challenging compared to the other species and we could clearly discriminate CWD affected animals from healthy controls. A slightly less efficient detection of CWD prions was observed using Syrian hamster PrP. By using bank vole PrP we could detect prions in brain samples of reindeer that had tested negative with traditional diagnostic tests. Moreover, we efficiently detected $\mathrm{PrP}^{\mathrm{Sc}}$ in samples from North American cervids, which have CWD prion strains that might be different from those found in Norway ${ }^{9}$. Thus, the use of bank vole PrP overcomes strain-related effects which are known to influence the efficiency of the RT-QuIC. The capability of bank vole PrP to detect a wide range of prion strains has already been reported ${ }^{100}$ and here we demonstrate for the first time that this substrate enables high efficient detection of multiple CWD strains in different Norwegian CWD affected cervids.

Efficient transmission of TSE infection requires a close similarity between the primary amino acid sequence of the $\mathrm{PrP}$ in the donor and in the recipient animal. This allows $\mathrm{PrP}^{\mathrm{sc}}$ to interact specifically with and convert the host's $\mathrm{PrP}^{\mathrm{C}}$ into the disease-associate isoform and could explain why CWD is so easily transmissible between different cervid species ${ }^{26,101,102}$. Our results showed that the efficiency of the RT-QuIC test was reduced by the use of deer PrP, especially in reindeer, and the sensitivity dropped drastically when using reindeer and elk PrP. Nevertheless, similar observations have been made in the field of human prion diseases: the use of human PrP substrate for RT-QuIC analyses results in lower sensitivity and specificity compared to Syrian hamster or bank vole $\mathrm{PrP}$ for detecting $\mathrm{Pr}^{\mathrm{Sc}}$ in peripheral tissues (e.g. cerebrospinal fluid and olfactory mucosa) of prion diseased patients $^{103-107}$. 
a

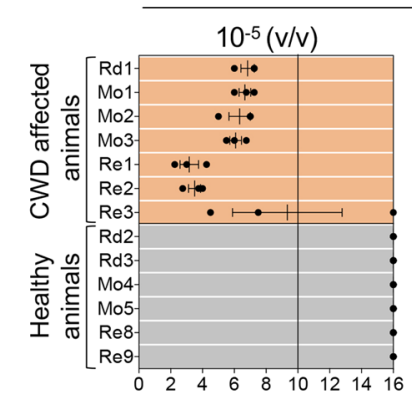

b

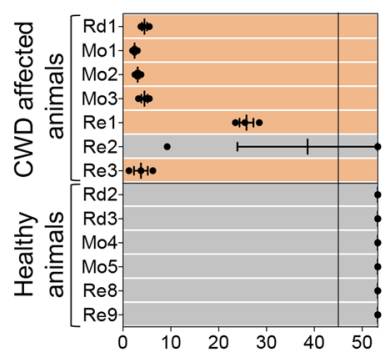

C

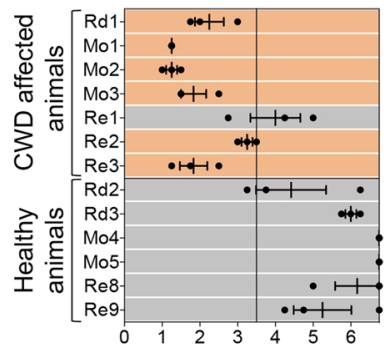

d

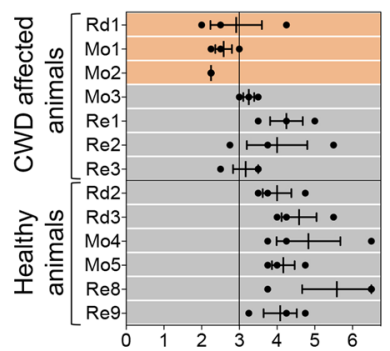

e

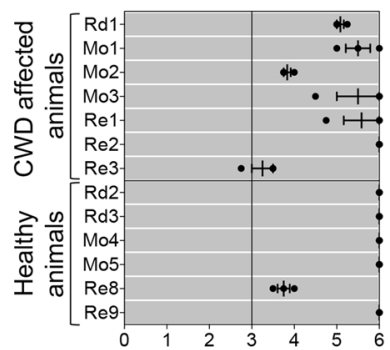

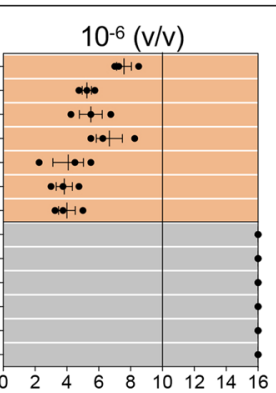

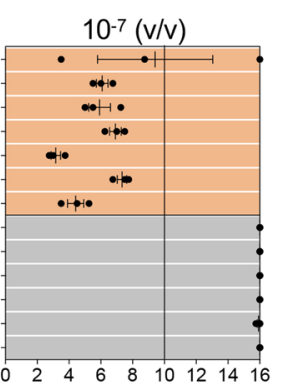

Bank vole

PrP (90-231)
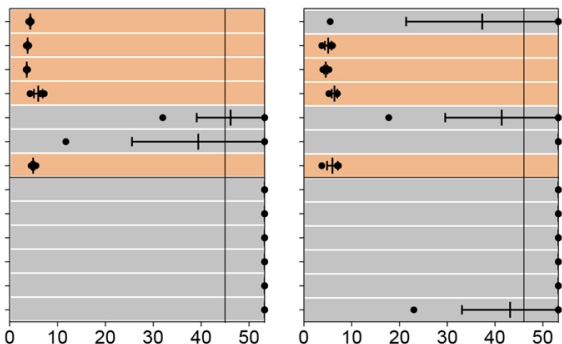

Syrian hamster

PrP(90-231)
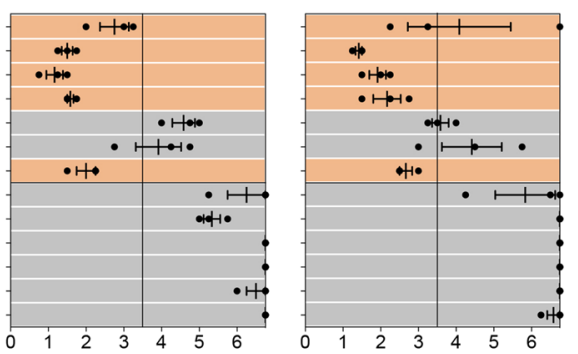

Deer

PrP(94-234)
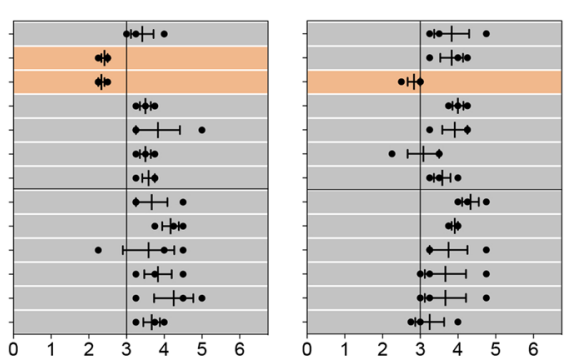

\section{Reindeer}

PrP(94-234)
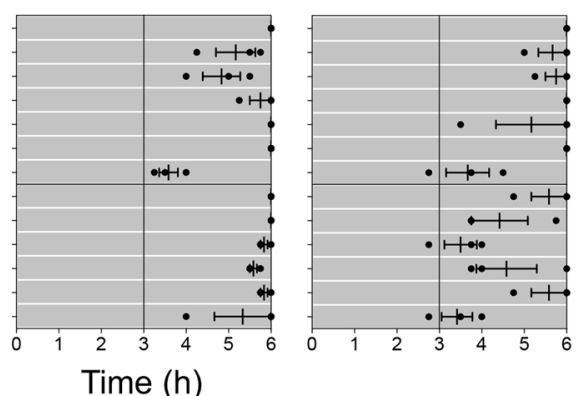

Elk

$\operatorname{PrP}(94-234)$

Figure 3. RT-QuIC results of CWD affected animals with detectable PrPsc in the brain. RT-QuIC analysis of serial brain homogenate dilutions (from $10^{-5}$ to $10^{-7}$ ) from CWD affected animals and controls with (a) bank vole, (b) Syrian hamster, (c) deer, (d) reindeer and (e) elk recombinant truncated PrP. Each sample was analyzed in triplicate and black dots indicate the time taken for each replicate to reach the fluorescence threshold (lag phase). The vertical line indicates the time threshold set up for each PrP substrate. Rd: red deer, Mo: moose; Re: reindeer. Mean value and standard error of the mean (S.E.M) are shown.

PrP sequences of other species, including human and non-cervid ruminants, are dissimilar to that of cervids and this limits the efficiency of interspecies CWD transmission. Nevertheless, the potential risk of interspecies transmission of CWD represents a serious public health concern since humans, cattle and sheep could be exposed to CWD prions through the consumption of prion-infected feed or from contact with a prion-contaminated 


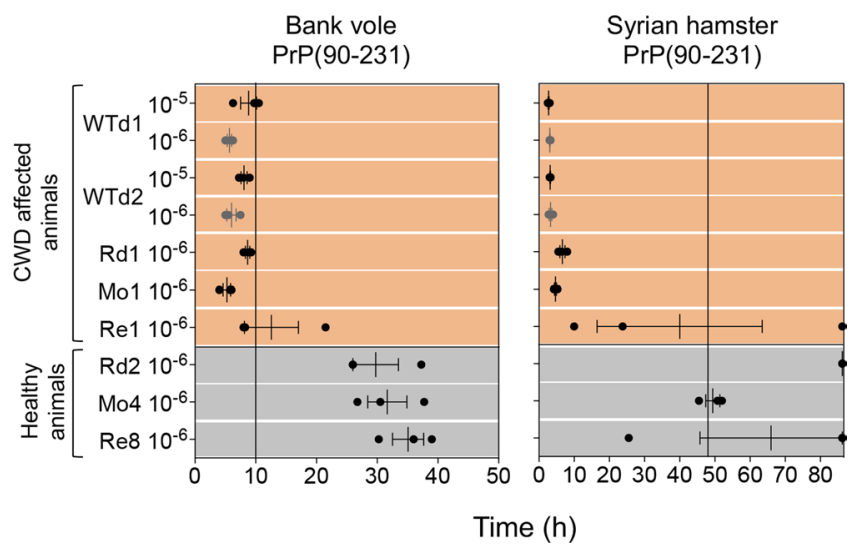

Figure 4. RT-QuIC results of CWD affected Norwegian and North American cervid species. Brain homogenates were diluted at $10^{-5}$ and/or $10^{-6}$ and analyzed by RT-QuIC using bank vole and Syrian hamster recombinant truncated $\mathrm{PrP}$. Each sample was analyzed in triplicate and black dots indicate the time taken for each replicate to reach the fluorescence threshold (lag phase). The vertical line indicates the time threshold set up for each PrP substrate. WTd: white tailed deer (North America); Rd: red deer; Mo: moose; Re: reindeer. Mean value and standard error of the mean (S.E.M) are shown.

environment. It is estimated that more than $60 \%$ of Americans have eaten deer or elk meat or their derived products ${ }^{108}$ while a large number of cattle, sheep and goats have grazed in CWD contaminated environments. Thankfully, controlled natural exposure studies and targeted surveillance programs currently indicate no cases of natural interspecies transmission of CWD ${ }^{10,109-113}$.

Experimentally, CWD can efficiently be transmitted by intracerebral inoculation in mice, mink, squirrel monkeys, ferrets, sheep and some cattle ${ }^{10,109,114-118}$. But attempts to transmit to transgenic mice overexpressing human prion protein ${ }^{119}$ or to Cynomologus macaques ${ }^{120}$, which are evolutionarily closer to humans, were unsuccessful. This suggests little or no zoonotic potential. The efficiency of CWD transmission to humans has been also evaluated in vitro with highly sensitive PMCA and RT-QuIC techniques. Some studies showed that the human PrP can be converted to the pathologic form by CWD prions. It was suggested that the efficiency of this conversion is highly influenced by (i) human PrP polymorphism (recipient), (ii) cervid PrP polymorphism (donor) and (iii) isolates origin (strain) $)^{121-125}$. Overall, experiments performed using in vitro amplification techniques suggest that the species barrier between cervids and human is not absolute. However, although these techniques mimic in vitro the process of prion conversion, they lack many of the biological interactions occurring in vivo and the results, regarding the study of the complex phenomenon of the species barrier, should be carefully interpreted. In addition, the species barrier does not only depend on the PrP sequence homology between host and recipient, but also the prion strain. It is therefore conceivable that different CWD strains may have different abilities at crossing the species barrier. Many other factors may play a pivotal role in driving this phenomenon. CWD prions can undergo to processes of selection and adaptation once the interspecies transmission has occurred, with the generation of new prion conformers more prone to propagate in the new host and likely easier to transmit within the species ${ }^{126,127}$. For instance, prions from cattle affected by bovine spongiform encephalopathy (BSE) crossed the species barrier (although with low efficiency) and infected humans, generating a new disease named variant Creutzfeldt-Jakob disease (vCJD) ${ }^{128}$. There is therefore considerable concern that CWD prions could cross the species barrier, adapt to humans and result in new forms of prion disease. The ongoing surveillance has not reported any documented cases of CWD transmission to humans at present. However, the lack of interspecies transmission cannot definitively be ruled out ${ }^{112,129}$.

Our optimized RT-QuIC performed with bank vole PrP could be used as first step screening assay followed by traditional confirmatory TeSeE ELISA, WB or IHC assays to increase the accuracy of CWD detection in affected animals. After a process of validation where many more samples of CWD affected animals and negative controls will be analyzed with this technique, it could be employed as new tool for the diagnosis of CWD either at clinical or preclinical stage of the disease. In addition, considering its elevated analytical sensitivity and rapidity, RT-QuIC might also be exploited for a quick and efficient $\mathrm{PrP}^{\mathrm{Sc}}$ detection in tissues and biological fluids, such as urine, saliva or feces. These samples are easier to collect than CNS and lymphoid tissues and do not require immobilization or euthanasia of animals. This test could also be used to confirm the absence of infection in animals prior to restocking. Finally, other than monitoring the spreading of CWD prions between cervid species, RT-QuIC with bank vole PrP can be further extended to evaluate the presence of prions in tissues collected from other animals (e.g. sheep, goats, cattle) eventually exposed to contaminated environment.

In conclusion, we provide evidence that RT-QuIC performed with bank vole $\mathrm{PrP}$ as reaction substrate is capable of detecting CWD prions, regardless of the cervid species, strains and geographical origin, with good analytical sensitivity and specificity. This rapid and useful technique is, in combination with traditional diagnostic tests, ideal for screening samples containing low concentrations of CWD prions. 

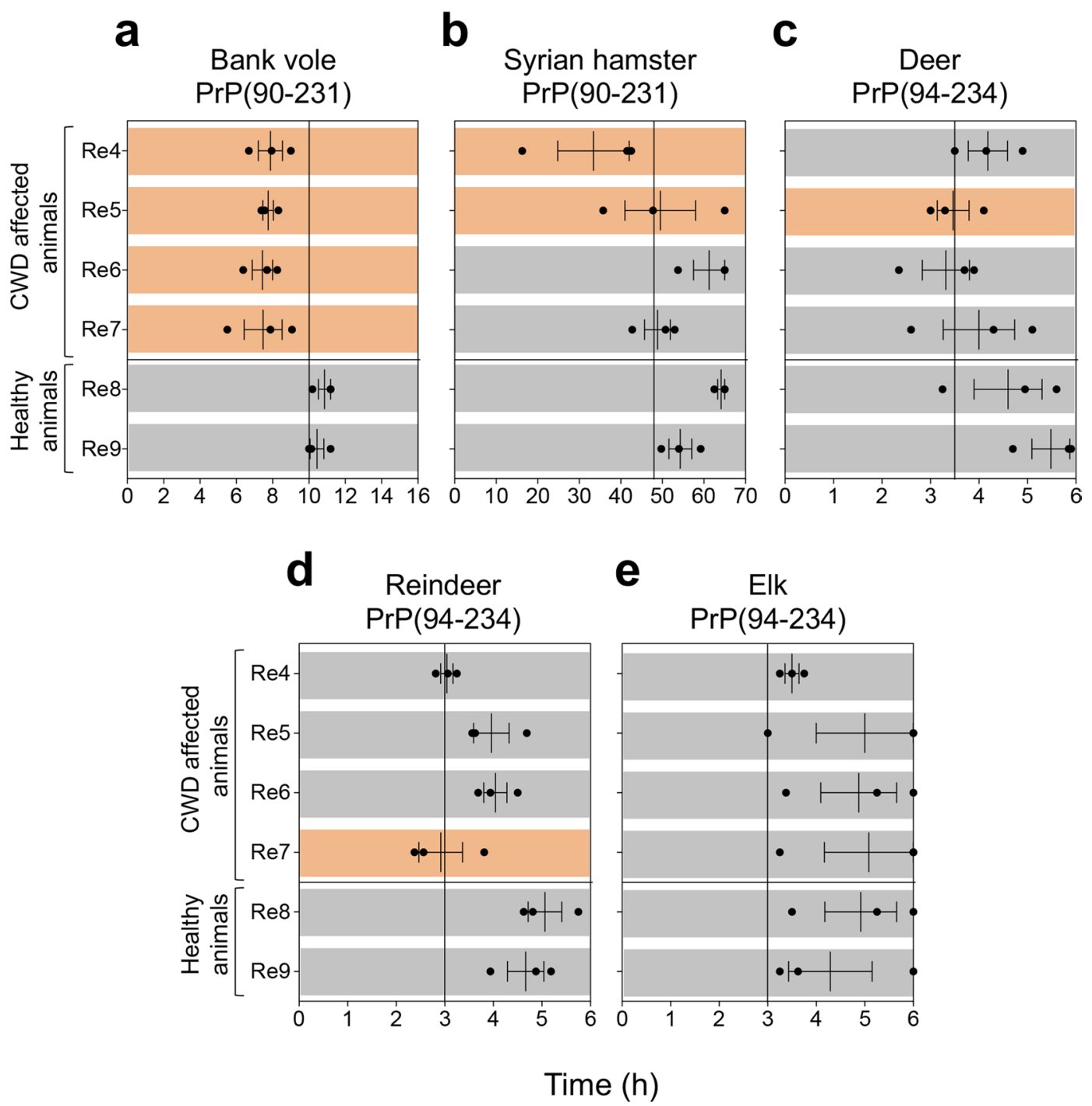

Figure 5. RT-QuIC results of CWD affected reindeer where $\mathrm{PrP}^{\mathrm{Sc}}$ was not biochemically detected in the brain. Brain homogenates were diluted at $10^{-5}$ and analyzed by RT-QuIC using (a) bank vole, (b) Syrian hamster, (c) deer, (d) reindeer and (e) elk recombinant truncated PrP. Each sample was analyzed in triplicate and black dots indicate the time to reach the fluorescence threshold (lag-phase) of each replicate. The vertical line indicates the time threshold set up for each PrP substrate. Rd: red deer; Mo: moose; Re: reindeer. Mean value and standard error of the mean (S.E.M) are shown.

\section{Materials and Methods}

Compliance with Ethical Standards. All animal samples included in this study were provided by the Norwegian surveillance program for CWD in compliance with ethical standards.

Animals. The following animals from Norway were included in the study: (i) 5 Moose (Alces alces) ( 3 affected by CWD and 2 healthy animals), (ii) 3 red deer (Cervus elaphus) ( 1 affected by CWD and 2 healthy animals) and (iii) 9 reindeer (Rangifer tarandus tarandus) (7 affected by CWD and 2 healthy animals). The information concerning the animal's geographical origin, sex, age and diagnostic status is summarized in Table 2.

TeSeE ${ }^{\text {TM }}$ ELISA and WB tests for CWD diagnosis. All the CWD affected animals were first detected by the Norwegian surveillance program for CWD, using commercially available tests for the detection of $\operatorname{PrP}^{\mathrm{Sc}}$. Brain tissues and a piece of lymph node were homogenized at 20\% (weight/volume) in individual grinding tubes. Rapid test TeSeE ${ }^{\mathrm{TM}}$ SAP ELISA (Bio-Rad) was carried out according to the manufacturer's instruction. Positive ELISA samples were then analyzed with $\mathrm{TeSeE}^{\mathrm{TM}}$ Western blot (Bio-Rad) for confirmation.

TeSeE $^{\mathrm{TM}}$ Western blot analysis of brain and lymph nodes samples. The homogenates submitted to Western blot were collected from the grinding tubes primarily analyzed by rapid test TeSeE ${ }^{\mathrm{TM}}$ ELISA. The WB test was performed, with slight modifications, according to the manufacturer's instructions. Briefly, $\operatorname{PrP}^{\mathrm{C}} \mathrm{Was}^{\mathrm{W}}$ 
digested by incubating the homogenates with Proteinase $\mathrm{K}(20 \mu \mathrm{l}$ per $\mathrm{ml})$ for $10 \mathrm{~min}$ at $37^{\circ} \mathrm{C}$. Electrophoresis was performed using mini-PROTEAN ${ }^{\circledR}$ TGX $^{\mathrm{TM}}$ Precast Gels (Bio-Rad) and Power Pac Universal (first 10 min at $60 \mathrm{~V}$ followed by approximately $35 \mathrm{~min}$ at $120 \mathrm{~V}$ ). Gels were then electroblotted using semi-dry transfer apparatus (Trans-Blot ${ }^{\circledR}$ Turbo ${ }^{\text {TM }}$ Transfer System, Bio-Rad) onto polyvinylidene fluoride (PVDF) membrane (Bio-Rad). The immunoblotting process began by blocking the membrane, to prevent unspecific bindings, with the kit's block solution for $30 \mathrm{~min}$, then a second $30 \mathrm{~min}$ incubation was carried out using monoclonal antibodies SHa31 (AbI from the kit) and an additional monoclonal antibody (P4) at a dilution of 1:1000. Lastly, a 20 min incubation with goat anti-mouse immunoglobulin G (IgG) antibody conjugated with horseradish peroxidase (AbII from the kit) was carried out. The test's chemiluminescent substrate ECL (Western blotting detecting reagents, Amersham $\mathrm{ECL}^{\mathrm{TM}}$ ) was then added and the chemiluminescent signals were visualized using ChemiDoc System (Bio-Rad). The samples were declared positive if characteristic banding patterns of PK-resistant core of PrP $\mathrm{P}^{\mathrm{Sc}}$ were present.

RT-QuIC recombinant substrates production. Truncated Syrian hamster (90-231), reindeer (94-234; 176D), deer (94-234; $96 \mathrm{G})$, elk (94-234; $132 \mathrm{M})$ and bank vole PrP (90-231; 109 M) constructs were purchased from GenScript. The constructs were expressed in Escherichia coli BL21 (DE3) cells (Stratagene). Freshly transformed overnight culture was inoculated into Luria Bertani (LB) medium and $100 \mu \mathrm{g} / \mathrm{mL}$ ampicillin. At 0.8 OD600 expression was induced with isopropyl b-D galactopyranoside (IPTG) to a final concentration of $0.75 \mathrm{mM}$. Cells were grown in a BioStat-B plus fermentor (Sartorius). The cells were lysed by a homogenizer (PandaPLUS 2000) and the inclusion bodies were suspended in buffer containing $25 \mathrm{mM}$ Tris- HCl, $5 \mathrm{mM}$ EDTA, $0.8 \%$ TritonX100, $\mathrm{pH} 8$, and then in bi-distilled water several times. Inclusion bodies containing recombinant proteins were dissolved in 5 volumes of $8 \mathrm{M}$ guanidine hydrochloride $(\mathrm{GndHCl})$, loaded onto pre-equilibrated HiLoad 26/60 Superdex 200-pg column, and eluted in $25 \mathrm{mM}$ Tris- $\mathrm{HCl}$ (pH 8), $5 \mathrm{mM}$ ethylenediaminetetraacetic acid (EDTA), and $6 \mathrm{M} \mathrm{GndHCl}$ at a flow/rate of $2 \mathrm{~mL} / \mathrm{min}$. Proteins refolding was performed by dialysis against refolding buffer $(20 \mathrm{mM}$ sodium acetate and $0.005 \% \mathrm{NaN} 3$ ( $\mathrm{pH}$ 5.5)) using a Spectrapor membrane. Purified proteins were analyzed by SDS-polyacrylamide gel electrophoresis under reducing conditions and Western blot. Aliquots of the recombinant proteins were stored at $-80^{\circ} \mathrm{C}$ in $10 \mathrm{mM}$ phosphate buffer (pH 5.8).

Preparation of the samples for RT-QuIC analyses. Brain tissues were homogenized at 10\% (weight/ volume) in Bio Rad buffer (from TeSeE ${ }^{\mathrm{TM}}$ grinding tubes), serially diluted (from $10^{-5}$ to $10^{-7}$ ) and subjected to RT-QuIC analysis. Two brain tissues of CWD affected white tailed deer (WTd) collected from North America (used for a ring trial for CWD diagnosis in 2006) were homogenized, diluted at $10^{-5}$ and $10^{-6}$ and included in the analysis.

RT-QuIC experimental procedures. Protein substrate solutions were allowed to thaw at room temperature and filtered through a $100 \mathrm{kDa}$ Nanosep centrifugal device (Pall Corporation). Samples were analyzed in triplicate in a black 96-well optical flat bottom plate (ThermoScientific). The final reaction volume was $100 \mu \mathrm{L}$ and the reagents (Sigma) were concentrated as follow: $150 \mathrm{mM} \mathrm{NaCl}, 0.002 \%$ SDS, $10 \mathrm{mM}$ PBS, $1 \mathrm{mM}$ EDTA, $10 \mu \mathrm{M}$ ThT and $0.13 \mathrm{mg} / \mathrm{ml}$ of recPrP. To avoid contamination, reaction mixes were prepared and loaded $(98 \mu \mathrm{L})$ onto the microplate in a prion-free laboratory. After the addition of $2 \mu \mathrm{L}$ of diluted brain homogenates (from $10^{-5}$ to $10^{-7}$ ), the plate was sealed with a sealing film (ThermoScientific) and inserted into a FLUOstar OPTIMA microplate reader (BMG Labtech). The plate was incubated at $55^{\circ} \mathrm{C}$ with cycles of 1 min shaking (at $600 \mathrm{rpm}$, double orbital) and $1 \mathrm{~min}$ incubation. Fluorescence readings $(480 \mathrm{~nm}$ ) were taken every $15 \mathrm{~min}$ (30 flashes per well at $450 \mathrm{~nm}$ ). A sample was considered positive if the two highest fluorescence values (AU) of the replicates were greater than 10.000 AU and at least two, out of three replicates, crossed the time threshold that was set for each recombinant substrate. We set the following time thresholds for each PrP: (i) Syrian hamster 48 hours, (ii) bank vole 10 hours, (iii) deer 3.5 hours, (iv) reindeer 3 hours and (v) elk 3 hours. In particular, we have evaluated the time at which the unspecific aggregation of each PrP template occurred in the presence of negative samples (analyzed at least three different times). We have then set this value as time-threshold. Therefore, all samples able to promote PrP aggregation before this time-threshold were considered able to exert a seeding activity while the others were considered unable to promote a seeding activity for each PrP substrate. Data are plotted in graphs showing the time taken for each replicate (black dots) to reach the fluorescence threshold (lag phase).

Statistical analyses and graphic representation. Statistical analysis (mean and standard error of the mean (S.E.M.)) and graphic representations of our data were performed using the Prism software (v5.0 GraphPad).

\section{Data availability}

All data generated or analyzed during this study are included in this published article.

Received: 6 October 2019; Accepted: 22 November 2019;

Published online: 09 December 2019

\section{References}

1. Haley, N. J. \& Hoover, E. A. Chronic wasting disease of cervids: current knowledge and future perspectives. Annu Rev Anim Biosci 3, 305-325, https://doi.org/10.1146/annurev-animal-022114-111001 (2015).

2. Sohn, H. J. et al. A case of chronic wasting disease in an elk imported to Korea from Canada. J Vet Med Sci 64, 855-858, https://doi. org/10.1292/jvms.64.855 (2002).

3. Benestad, S. L., Mitchell, G., Simmons, M., Ytrehus, B. \& Vikoren, T. First case of chronic wasting disease in Europe in a Norwegian free-ranging reindeer. Vet Res 47, 88, https://doi.org/10.1186/s13567-016-0375-4 (2016). 
4. Race, B., Williams, K. \& Chesebro, B. Transmission studies of chronic wasting disease to transgenic mice overexpressing human prion protein using the RT-QuIC assay. Vet Res 50, 6, https://doi.org/10.1186/s13567-019-0626-2 (2019).

5. Osterholm, M. T. et al. Chronic Wasting Disease in Cervids: Implications for Prion Transmission to Humans and Other Animal Species. MBio 10, https://doi.org/10.1128/mBio.01091-19 (2019).

6. Williams, E. S. \& Young, S. Neuropathology of chronic wasting disease of mule deer (Odocoileus hemionus) and elk (Cervus elaphus nelsoni). Vet Pathol 30, 36-45, https://doi.org/10.1177/030098589303000105 (1993).

7. Samuel, M. D. \& Storm, D. J. Chronic wasting disease in white-tailed deer: infection, mortality, and implications for heterogeneous transmission. Ecology 97, 3195-3205, https://doi.org/10.1002/ecy.1538 (2016).

8. Ball, K. Chronic wasting disease in a Rocky Mountain elk. Can Vet J 43, 880-882 (2002).

9. Pirisinu, L. et al. Novel Type of Chronic Wasting Disease Detected in Moose (Alces alces), Norway. Emerg Infect Dis 24, 2210-2218, https://doi.org/10.3201/eid2412.180702 (2018).

10. Saunders, S. E., Bartelt-Hunt, S. L. \& Bartz, J. C. Occurrence, transmission, and zoonotic potential of chronic wasting disease. Emerg Infect Dis 18, 369-376, https://doi.org/10.3201/eid1803.110685 (2012).

11. Moore, S. J. et al. Horizontal Transmission of Chronic Wasting Disease in Reindeer. Emerg Infect Dis 22, 2142-2145, https://doi. org/10.3201/eid2212.160635 (2016).

12. Gilch, S. et al. Chronic wasting disease. Top Curr Chem 305, 51-77, https://doi.org/10.1007/128_2011_159 (2011).

13. Prusiner, S. B. Novel proteinaceous infectious particles cause scrapie. Science 216, 136-144 (1982).

14. Spraker, T. R. et al. Spongiform encephalopathy in free-ranging mule deer (Odocoileus hemionus), white-tailed deer (Odocoileus virginianus) and Rocky Mountain elk (Cervus elaphus nelsoni) in northcentral Colorado. J Wildl Dis 33, 1-6, https://doi. org/10.7589/0090-3558-33.1.1 (1997).

15. Spraker, T. R. et al. Distribution of protease-resistant prion protein and spongiform encephalopathy in free-ranging mule deer (Odocoileus hemionus) with chronic wasting disease. Vet Pathol 39, 546-556, https://doi.org/10.1354/vp.39-5-546 (2002).

16. Williams, E. S. Scrapie and chronic wasting disease. Clin Lab Med 23, 139-159 (2003).

17. Williams, E. S. \& Young, S. Spongiform encephalopathies in Cervidae. Rev Sci Tech 11, 551-567 (1992).

18. Williams, E. S. \& Young, S. Spongiform encephalopathy of Rocky Mountain elk. J Wildl Dis 18, 465-471 (1982).

19. Legname, G. Elucidating the function of the prion protein. PLoS Pathog 13, e1006458, https://doi.org/10.1371/journal. ppat.1006458 (2017).

20. Cohen, F. E. \& Prusiner, S. B. Pathologic conformations of prion proteins. Annu Rev Biochem 67, 793-819, https://doi.org/10.1146/ annurev.biochem.67.1.793 (1998).

21. Prusiner, S. B. Molecular biology of prion diseases. Science 252, 1515-1522 (1991).

22. Mabbott, N. A. How do $\operatorname{PrP}(\mathrm{Sc})$ Prions Spread between Host Species, and within Hosts? Pathogens 6, https://doi.org/10.3390/ pathogens6040060 (2017).

23. Miller, M. W., Williams, E. S., Hobbs, N. T. \& Wolfe, L. L. Environmental sources of prion transmission in mule deer. Emerg Infect Dis 10, 1003-1006, https://doi.org/10.3201/eid1006.040010 (2004).

24. Selariu, A. et al. In utero transmission and tissue distribution of chronic wasting disease-associated prions in free-ranging Rocky Mountain elk. J Gen Virol 96, 3444-3455, https://doi.org/10.1099/jgv.0.000281 (2015).

25. Otero, A. et al. Prion protein polymorphisms associated with reduced CWD susceptibility limit peripheral PrP(CWD) deposition in orally infected white-tailed deer. BMC Vet Res 15, 50, https://doi.org/10.1186/s12917-019-1794-z (2019).

26. O’Rourke, K. I. et al. PrP genotypes of captive and free-ranging Rocky Mountain elk (Cervus elaphus nelsoni) with chronic wasting disease. J Gen Virol 80(Pt 10), 2765-2769, https://doi.org/10.1099/0022-1317-80-10-2765 (1999).

27. O'Rourke, K. I. et al. Polymorphisms in the prion precursor functional gene but not the pseudogene are associated with susceptibility to chronic wasting disease in white-tailed deer. J Gen Virol 85, 1339-1346, https://doi.org/10.1099/vir.0.79785-0 (2004).

28. Johnson, C. et al. Prion protein polymorphisms in white-tailed deer influence susceptibility to chronic wasting disease. J Gen Virol 87, 2109-2114, https://doi.org/10.1099/vir.0.81615-0 (2006).

29. Wilson, G. A. et al. Polymorphisms at the PRNP gene influence susceptibility to chronic wasting disease in two species of deer (Odocoileus Spp.) in western Canada. J Toxicol Environ Health A 72, 1025-1029, https://doi.org/10.1080/15287390903084264 (2009).

30. Johnson, C. J. et al. Prion protein polymorphisms affect chronic wasting disease progression. PLoS One 6, e17450, https://doi. org/10.1371/journal.pone.0017450 (2011).

31. Wik, L. et al. Polymorphisms and variants in the prion protein sequence of European moose (Alces alces), reindeer (Rangifer tarandus), roe deer (Capreolus capreolus) and fallow deer (Dama dama) in Scandinavia. Prion 6, 256-260, https://doi.org/10.4161/ pri.19641 (2012).

32. Jewell, J. E., Conner, M. M., Wolfe, L. L., Miller, M. W. \& Williams, E. S. Low frequency of PrP genotype 225SF among free-ranging mule deer (Odocoileus hemionus) with chronic wasting disease. J Gen Virol 86, 2127-2134, https://doi.org/10.1099/vir.0.81077-0 (2005).

33. O’Rourke, K. I. et al. Elk with a long incubation prion disease phenotype have a unique PrPd profile. Neuroreport 18, 1935-1938, https://doi.org/10.1097/WNR.0b013e3282f1ca2f (2007).

34. Robinson, S. J., Samuel, M. D., O'Rourke, K. I. \& Johnson, C. J. The role of genetics in chronic wasting disease of North American cervids. Prion 6, 153-162, https://doi.org/10.4161/pri.19640 (2012).

35. Angers, R. C. et al. Prion strain mutation determined by prion protein conformational compatibility and primary structure. Science 328, 1154-1158, https://doi.org/10.1126/science.1187107 (2010).

36. Perrott, M. R., Sigurdson, C. J., Mason, G. L. \& Hoover, E. A. Evidence for distinct chronic wasting disease (CWD) strains in experimental CWD in ferrets. J Gen Virol 93, 212-221, https://doi.org/10.1099/vir.0.035006-0 (2012).

37. Bian, J. et al. Primary structural differences at residue 226 of deer and elk PrP dictate selection of distinct CWD prion strains in gene-targeted mice. Proc Natl Acad Sci USA 116, 12478-12487, https://doi.org/10.1073/pnas.1903947116 (2019).

38. Bessen, R. A. \& Marsh, R. F. Identification of two biologically distinct strains of transmissible mink encephalopathy in hamsters. J Gen Virol 73(Pt 2), 329-334, https://doi.org/10.1099/0022-1317-73-2-329 (1992).

39. Bessen, R. A. \& Marsh, R. F. Distinct PrP properties suggest the molecular basis of strain variation in transmissible mink encephalopathy. J Virol 68, 7859-7868 (1994)

40. Bruce, M. E. \& Fraser, H. Scrapie strain variation and its implications. Curr Top Microbiol Immunol 172, 125-138 (1991)

41. Bruce, M. E. Scrapie strain variation and mutation. Br Med Bull 49, 822-838, https://doi.org/10.1093/oxfordjournals.bmb.a072649 (1993).

42. Bruce, M. E., McConnell, I., Fraser, H. \& Dickinson, A. G. The disease characteristics of different strains of scrapie in Sinc congenic mouse lines: implications for the nature of the agent and host control of pathogenesis. J Gen Virol 72(Pt 3), 595-603, https://doi. org/10.1099/0022-1317-72-3-595 (1991).

43. Fraser, H. \& Dickinson, A. G. Scrapie in mice. Agent-strain differences in the distribution and intensity of grey matter vacuolation. J Comp Pathol 83, 29-40 (1973).

44. Herbst, A., Velasquez, C. D., Triscott, E., Aiken, J. M. \& McKenzie, D. Chronic Wasting Disease Prion Strain Emergence and Host Range Expansion. Emerg Infect Dis 23, 1598-1600, https://doi.org/10.3201/eid2309.161474 (2017). 
45. Duque Velasquez, C. et al. Deer Prion Proteins Modulate the Emergence and Adaptation of Chronic Wasting Disease Strains. J Virol 89, 12362-12373, https://doi.org/10.1128/JVI.02010-15 (2015).

46. Meyerett, C. et al. In vitro strain adaptation of CWD prions by serial protein misfolding cyclic amplification. Virology 382, 267-276, https://doi.org/10.1016/j.virol.2008.09.023 (2008).

47. Peters, J., Miller, J. M., Jenny, A. L., Peterson, T. L. \& Carmichael, K. P. Immunohistochemical diagnosis of chronic wasting disease in preclinically affected elk from a captive herd. J Vet Diagn Invest 12, 579-582, https://doi.org/10.1177/104063870001200618 (2000).

48. Sigurdson, C. J. et al. Oral transmission and early lymphoid tropism of chronic wasting disease PrPres in mule deer fawns (Odocoileus hemionus). J Gen Virol 80(Pt 10), 2757-2764, https://doi.org/10.1099/0022-1317-80-10-2757 (1999).

49. Keane, D. P. et al. Comparison of retropharyngeal lymph node and obex region of the brainstem in detection of chronic wasting disease in white-tailed deer (Odocoileus virginianus). J Vet Diagn Invest 20, 58-60, https://doi.org/10.1177/104063870802000110 (2008).

50. Guiroy, D. C., Williams, E. S., Yanagihara, R. \& Gajdusek, D. C. Topographic distribution of scrapie amyloid-immunoreactive plaques in chronic wasting disease in captive mule deer (Odocoileus hemionus hemionus). Acta Neuropathol 81, 475-478 (1991).

51. Guiroy, D. C., Williams, E. S., Song, K. J., Yanagihara, R. \& Gajdusek, D. C. Fibrils in brain of Rocky Mountain elk with chronic wasting disease contain scrapie amyloid. Acta Neuropathol 86, 77-80 (1993).

52. Hibler, C. P. et al. Field validation and assessment of an enzyme-linked immunosorbent assay for detecting chronic wasting disease in mule deer (Odocoileus hemionus), white-tailed deer (Odocoileus virginianus), and Rocky Mountain elk (Cervus elaphus nelsoni). J Vet Diagn Invest 15, 311-319, https://doi.org/10.1177/104063870301500402 (2003).

53. Fox, K. A., Jewell, J. E., Williams, E. S. \& Miller, M. W. Patterns of PrPCWD accumulation during the course of chronic wasting disease infection in orally inoculated mule deer (Odocoileus hemionus). J Gen Virol 87, 3451-3461, https://doi.org/10.1099/ vir.0.81999-0 (2006)

54. van Keulen, L. J. et al. Immunohistochemical detection of prion protein in lymphoid tissues of sheep with natural scrapie. J Clin Microbiol 34, 1228-1231 (1996).

55. Wild, M. A., Spraker, T. R., Sigurdson, C. J., O’Rourke, K. I. \& Miller, M. W. Preclinical diagnosis of chronic wasting disease in captive mule deer (Odocoileus hemionus) and white-tailed deer (Odocoileus virginianus) using tonsillar biopsy. J Gen Virol 83, 2629-2634, https://doi.org/10.1099/0022-1317-83-10-2629 (2002).

56. Keane, D. et al. Validation of use of rectoanal mucosa-associated lymphoid tissue for immunohistochemical diagnosis of chronic wasting disease in white-tailed deer (Odocoileus virginianus). J Clin Microbiol 47, 1412-1417, https://doi.org/10.1128/JCM.0220908 (2009).

57. Wolfe, L. L. et al. PrPCWD in rectal lymphoid tissue of deer (Odocoileus spp.). J Gen Virol 88, 2078-2082, https://doi.org/10.1099/ vir.0.82342-0 (2007).

58. Spraker, T. R., Balachandran, A., Zhuang, D. \& O'Rourke, K. I. Variable patterns of distribution of $\operatorname{PrP}(C W D)$ in the obex and cranial lymphoid tissues of Rocky Mountain elk (Cervus elaphus nelsoni) with subclinical chronic wasting disease. Vet Rec 155, 295-302, https://doi.org/10.1136/vr.155.10.295 (2004).

59. Monello, R. J. et al. Efficacy of antemortem rectal biopsies to diagnose and estimate prevalence of chronic wasting disease in freeranging cow elk (Cervus elaphus nelsoni). J Wildl Dis 49, 270-278, https://doi.org/10.7589/2011-12-362 (2013).

60. Davenport, K. A. et al. Comparative analysis of prions in nervous and lymphoid tissues of chronic wasting disease-infected cervids. J Gen Virol 99, 753-758, https://doi.org/10.1099/jgv.0.001053 (2018).

61. EFSA Panel on Biological Hazards (BIOHAZ)Antonia. R. et al. Scientific opinion on chronic wasting disease (II). EFSA Journal, https://doi.org/10.2903/j.efsa.2018.5132 (2017).

62. Bae, S. E., Jung, S., Kim, H. Y. \& Son, H. S. Correlation analysis for the incubation period of prion disease. Prion 6, 276-281, https:// doi.org/10.4161/pri.19638 (2012).

63. Gibbs, C. J. Jr. et al. Creutzfeldt-Jakob disease (spongiform encephalopathy): transmission to the chimpanzee. Science 161, 388-389, https://doi.org/10.1126/science.161.3839.388 (1968)

64. Prusiner, S. B. et al. Transgenetic studies implicate interactions between homologous PrP isoforms in scrapie prion replication. Cell 63, 673-686 (1990).

65. Giles, K., Woerman, A. L., Berry, D. B. \& Prusiner, S. B. Bioassays and Inactivation of Prions. Cold Spring Harb Perspect Biol 9 , https://doi.org/10.1101/cshperspect.a023499 (2017).

66. Boerner, S., Wagenfuhr, K., Daus, M. L., Thomzig, A. \& Beekes, M. Towards further reduction and replacement of animal bioassays in prion research by cell and protein misfolding cyclic amplification assays. Lab Anim 47, 106-115, https://doi.org/10.1177/ 0023677213476856 (2013).

67. Daus, M. L. et al. Presence and seeding activity of pathological prion protein $(\operatorname{PrP}(\mathrm{TSE}))$ in skeletal muscles of white-tailed deer infected with chronic wasting disease. PLoS One 6, e18345, https://doi.org/10.1371/journal.pone.0018345 (2011).

68. Pulford, B. et al. Detection of PrPCWD in feces from naturally exposed Rocky Mountain elk (Cervus elaphus nelsoni) using protein misfolding cyclic amplification. J Wildl Dis 48, 425-434, https://doi.org/10.7589/0090-3558-48.2.425 (2012).

69. Denkers, N. D., Henderson, D. M., Mathiason, C. K. \& Hoover, E. A. Enhanced prion detection in biological samples by magnetic particle extraction and real-time quaking-induced conversion. J Gen Virol 97, 2023-2029, https://doi.org/10.1099/jgv.0.000515 (2016).

70. Davenport, K. A., Hoover, C. E., Denkers, N. D., Mathiason, C. K. \& Hoover, E. A. Modified Protein Misfolding Cyclic Amplification Overcomes Real-Time Quaking-Induced Conversion Assay Inhibitors in Deer Saliva To Detect Chronic Wasting Disease Prions. J Clin Microbiol 56, https://doi.org/10.1128/JCM.00947-18 (2018).

71. Haley, N. J. et al. Prion-seeding activity in cerebrospinal fluid of deer with chronic wasting disease. PLoS One 8, e81488, https://doi. org/10.1371/journal.pone.0081488 (2013).

72. Kramm, C. et al. Detection of Prions in Blood of Cervids at the Asymptomatic Stage of Chronic Wasting Disease. Sci Rep 7, 17241, https://doi.org/10.1038/s41598-017-17090-x (2017).

73. Haley, N. J., Mathiason, C. K., Zabel, M. D., Telling, G. C. \& Hoover, E. A. Detection of sub-clinical CWD infection in conventional test-negative deer long after oral exposure to urine and feces from CWD+ deer. PLoS One 4, e7990, https://doi.org/10.1371/ journal.pone.0007990 (2009).

74. Atarashi, R. et al. Simplified ultrasensitive prion detection by recombinant PrP conversion with shaking. Nat Methods 5, 211-212, https://doi.org/10.1038/nmeth0308-211 (2008).

75. Haley, N. J. et al. Antemortem Detection of Chronic Wasting Disease Prions in Nasal Brush Collections and Rectal Biopsy Specimens from White-Tailed Deer by Real-Time Quaking-Induced Conversion. J Clin Microbiol 54, 1108-1116, https://doi. org/10.1128/JCM.02699-15 (2016)

76. Haley, N. J. et al. Seeded Amplification of Chronic Wasting Disease Prions in Nasal Brushings and Recto-anal Mucosa-Associated Lymphoid Tissues from Elk by Real-Time Quaking-Induced Conversion. J Clin Microbiol 54, 1117-1126, https://doi.org/10.1128/ JCM.02700-15 (2016).

77. Elder, A. M. et al. In vitro detection of prionemia in TSE-infected cervids and hamsters. PLoS One 8, e80203, https://doi. org/10.1371/journal.pone.0080203 (2013).

78. Henderson, D. M. et al. Longitudinal Detection of Prion Shedding in Saliva and Urine by Chronic Wasting Disease-Infected Deer by Real-Time Quaking-Induced Conversion. J Virol 89, 9338-9347, https://doi.org/10.1128/JVI.01118-15 (2015). 
79. Henderson, D. M. et al. Rapid antemortem detection of CWD prions in deer saliva. PLoS One 8, e74377, https://doi.org/10.1371/ journal.pone.0074377 (2013).

80. John, T. R., Schatzl, H. M. \& Gilch, S. Early detection of chronic wasting disease prions in urine of pre-symptomatic deer by realtime quaking-induced conversion assay. Prion 7, 253-258, https://doi.org/10.4161/pri.24430 (2013).

81. Cheng, Y. C. et al. Early and Non-Invasive Detection of Chronic Wasting Disease Prions in Elk Feces by Real-Time Quaking Induced Conversion. PLoS One 11, e0166187, https://doi.org/10.1371/journal.pone.0166187 (2016).

82. Henderson, D. M. et al. Detection of chronic wasting disease prion seeding activity in deer and elk feces by real-time quakinginduced conversion. J Gen Virol 98, 1953-1962, https://doi.org/10.1099/jgv.0.000844 (2017).

83. Moreno, J. A. \& Telling, G. C. Molecular Mechanisms of Chronic Wasting Disease Prion Propagation. Cold Spring Harb Perspect Med 8, https://doi.org/10.1101/cshperspect.a024448 (2018).

84. Denkers, N. D., Seelig, D. M., Telling, G. C. \& Hoover, E. A. Aerosol and nasal transmission of chronic wasting disease in cervidized mice. J Gen Virol 91, 1651-1658, https://doi.org/10.1099/vir.0.017335-0 (2010).

85. Haley, N. J., Seelig, D. M., Zabel, M. D., Telling, G. C. \& Hoover, E. A. Detection of CWD prions in urine and saliva of deer by transgenic mouse bioassay. PLoS One 4, e4848, https://doi.org/10.1371/journal.pone.0004848 (2009).

86. Haley, N. J. et al. Detection of chronic wasting disease prions in salivary, urinary, and intestinal tissues of deer: potential mechanisms of prion shedding and transmission. J Virol 85, 6309-6318, https://doi.org/10.1128/JVI.00425-11 (2011).

87. Mathiason, C. K. et al. Infectious prions in the saliva and blood of deer with chronic wasting disease. Science 314, 133-136, https:// doi.org/10.1126/science.1132661 (2006).

88. Pritzkow, S. et al. Grass plants bind, retain, uptake, and transport infectious prions. Cell Rep 11, 1168-1175, https://doi. org/10.1016/j.celrep.2015.04.036 (2015).

89. Hannaoui, S., Schatzl, H. M. \& Gilch, S. Chronic wasting disease: Emerging prions and their potential risk. PLoS Pathog 13, e1006619, https://doi.org/10.1371/journal.ppat.1006619 (2017).

90. Gough, K. C. \& Maddison, B. C. Prion transmission: prion excretion and occurrence in the environment. Prion 4, 275-282, https:// doi.org/10.4161/pri.4.4.13678 (2010)

91. Almberg, E. S., Cross, P. C., Johnson, C. J., Heisey, D. M. \& Richards, B. J. Modeling routes of chronic wasting disease transmission: environmental prion persistence promotes deer population decline and extinction. PLoS One 6, e19896, https://doi.org/10.1371/ journal.pone.0019896 (2011).

92. Denkers, N. D., Telling, G. C. \& Hoover, E. A. Minor oral lesions facilitate transmission of chronic wasting disease. J Virol 85, 1396-1399, https://doi.org/10.1128/JVI.01655-10 (2011)

93. Johnson, C. J. et al. Prions adhere to soil minerals and remain infectious. PLoS Pathog 2, e32, https://doi.org/10.1371/journal. ppat.0020032 (2006)

94. Hill, A. F. et al. Species-barrier-independent prion replication in apparently resistant species. Proc Natl Acad Sci USA 97, 10248-10253 (2000).

95. Bistaffa, E., Rossi, M., De Luca, C. M. G. \& Moda, F. Biosafety of Prions. Prog Mol Biol Transl Sci 150, 455-485, https://doi. org/10.1016/bs.pmbts.2017.06.017 (2017).

96. Rossi, M., Baiardi, S. \& Parchi, P. Understanding Prion Strains: Evidence from Studies of the Disease Forms Affecting Humans. Viruses 11, https://doi.org/10.3390/v11040309 (2019).

97. Orru, C. D. et al. Factors That Improve RT-QuIC Detection of Prion Seeding Activity. Viruses 8, https://doi.org/10.3390/v8050140 (2016).

98. CDC. https://www.cdc.gov/prions/cwd/occurrence.html.

99. Fediaevsky, A. et al. A descriptive study of the prevalence of atypical and classical scrapie in sheep in 20 European countries. BMC Vet Res 4, 19, https://doi.org/10.1186/1746-6148-4-19 (2008).

100. Orru, C. D. et al. Bank Vole Prion Protein As an Apparently Universal Substrate for RT-QuIC-Based Detection and Discrimination of Prion Strains. PLoS Pathog 11, e1004983, https://doi.org/10.1371/journal.ppat.1004983 (2015).

101. Kaluz, S., Kaluzova, M. \& Flint, A. P. Sequencing analysis of prion genes from red deer and camel. Gene 199, 283-286, https://doi. org/10.1016/s0378-1119(97)00382-x (1997).

102. Cervenakova, L., Rohwer, R., Williams, S., Brown, P. \& Gajdusek, D. C. High sequence homology of the PrP gene in mule deer and Rocky Mountain elk. Lancet 350, 219-220, https://doi.org/10.1016/s0140-6736(05)62387-2 (1997).

103. Orru, C. D. et al. A test for Creutzfeldt-Jakob disease using nasal brushings. N Engl J Med 371, 519-529, https://doi.org/10.1056/ NEJMoa1315200 (2014)

104. Franceschini, A. et al. High diagnostic value of second generation CSF RT-QuIC across the wide spectrum of CJD prions. Sci Rep 7, 10655, https://doi.org/10.1038/s41598-017-10922-w (2017)

105. Redaelli, V. et al. Detection of prion seeding activity in the olfactory mucosa of patients with Fatal Familial Insomnia. Sci Rep 7, 46269, https://doi.org/10.1038/srep46269 (2017)

106. McGuire, L. I. et al. Real time quaking-induced conversion analysis of cerebrospinal fluid in sporadic Creutzfeldt-Jakob disease. Ann Neurol 72, 278-285, https://doi.org/10.1002/ana.23589 (2012).

107. McGuire, L. I. et al. Cerebrospinal fluid real-time quaking-induced conversion is a robust and reliable test for sporadic creutzfeldtjakob disease: An international study. Ann Neurol 80, 160-165, https://doi.org/10.1002/ana.24679 (2016).

108. Abrams, J. Y., Maddox, R. A., Harvey, A. R., Schonberger, L. B. \& Belay, E. D. Travel history, hunting, and venison consumption related to prion disease exposure, 2006-2007 FoodNet Population Survey. J Am Diet Assoc 111, 858-863, https://doi.org/10.1016/j. jada.2011.03.015 (2011)

109. Kurt, T. D. \& Sigurdson, C. J. Cross-species transmission of CWD prions. Prion 10, 83-91, https://doi.org/10.1080/19336896.2015 $1118603(2016)$

110. Belay, E. D. et al. Chronic wasting disease and potential transmission to humans. Emerg Infect Dis 10, 977-984, https://doi. org/10.3201/eid1006.031082 (2004).

111. Williams, E. S., O’Toole, D., Miller, M. W., Kreeger, T. J. \& Jewell, J. E. Cattle (Bos Taurus) Resist Chronic Wasting Disease Following Oral Inoculation Challenge or Ten Years' Natural Exposure in Contaminated Environments. J Wildl Dis 54, 460-470, https://doi. org/10.7589/2017-12-299 (2018).

112. Beringue, V., Vilotte, J. L. \& Laude, H. Prion agent diversity and species barrier. Vet Res 39, 47, https://doi.org/10.1051/ vetres:2008024 (2008).

113. Sigurdson, C. J. A prion disease of cervids: chronic wasting disease. Vet Res 39, 41, https://doi.org/10.1051/vetres:2008018 (2008).

114. Hamir, A. N. et al. Experimental transmission of chronic wasting disease agent from mule deer to cattle by the intracerebral route. J Vet Diagn Invest 17, 276-281, https://doi.org/10.1177/104063870501700313 (2005).

115. Harrington, R. D. et al. A species barrier limits transmission of chronic wasting disease to mink (Mustela vison). J Gen Virol 89, 1086-1096, https://doi.org/10.1099/vir.0.83422-0 (2008).

116. Marsh, R. F., Kincaid, A. E., Bessen, R. A. \& Bartz, J. C. Interspecies transmission of chronic wasting disease prions to squirrel monkeys (Saimiri sciureus). J Virol 79, 13794-13796, https://doi.org/10.1128/JVI.79.21.13794-13796.2005 (2005).

117. Race, B. et al. Chronic wasting disease agents in nonhuman primates. Emerg Infect Dis 20, 833-837, https://doi.org/10.3201/ eid2005.130778 (2014).

118. Hamir, A. N. et al. Transmission of chronic wasting disease of mule deer to Suffolk sheep following intracerebral inoculation. J Vet Diagn Invest 18, 558-565, https://doi.org/10.1177/104063870601800606 (2006). 
119. Sandberg, M. K. et al. Chronic wasting disease prions are not transmissible to transgenic mice overexpressing human prion protein. J Gen Virol 91, 2651-2657, https://doi.org/10.1099/vir.0.024380-0 (2010).

120. Race, B. et al. Susceptibilities of nonhuman primates to chronic wasting disease. Emerg Infect Dis 15, 1366-1376, https://doi. org/10.3201/eid1509.090253 (2009).

121. Kurt, T. D. et al. Human prion protein sequence elements impede cross-species chronic wasting disease transmission. JClin Invest 125, 1485-1496, https://doi.org/10.1172/JCI79408 (2015)

122. Barria, M. A., Libori, A., Mitchell, G. \& Head, M. W. Susceptibility of Human Prion Protein to Conversion by Chronic Wasting Disease Prions. Emerg Infect Dis 24, 1482-1489, https://doi.org/10.3201/eid2408.161888 (2018).

123. Barria, M. A., Telling, G. C., Gambetti, P., Mastrianni, J. A. \& Soto, C. Generation of a new form of human $\operatorname{PrP}(\mathrm{Sc})$ in vitro by interspecies transmission from cervid prions. J Biol Chem 286, 7490-7495, https://doi.org/10.1074/jbc.M110.198465 (2011).

124. Davenport, K. A. et al. Insights into Chronic Wasting Disease and Bovine Spongiform Encephalopathy Species Barriers by Use of Real-Time Conversion. J Virol 89, 9524-9531, https://doi.org/10.1128/JVI.01439-15 (2015).

125. Luers, L. et al. Seeded fibrillation as molecular basis of the species barrier in human prion diseases. PLoS One 8, e72623, https://doi. org/10.1371/journal.pone.0072623 (2013).

126. Bartz, J. C., Bessen, R. A., McKenzie, D., Marsh, R. F. \& Aiken, J. M. Adaptation and selection of prion protein strain conformations following interspecies transmission of transmissible mink encephalopathy. J Virol 74, 5542-5547, https://doi.org/10.1128/ jvi.74.12.5542-5547.2000 (2000).

127. Padilla, D. et al. Sheep and goat BSE propagate more efficiently than cattle BSE in human PrP transgenic mice. PLoS Pathog 7, e1001319, https://doi.org/10.1371/journal.ppat.1001319 (2011).

128. Hill, A. F. et al. The same prion strain causes vCJD and BSE. Nature 389(448-450), 526, https://doi.org/10.1038/38925 (1997).

129. Waddell, L. et al. Current evidence on the transmissibility of chronic wasting disease prions to humans-A systematic review. Transbound Emerg Dis 65, 37-49, https://doi.org/10.1111/tbed.12612 (2018).

130. Wilham, J. M. et al. Rapid end-point quantitation of prion seeding activity with sensitivity comparable to bioassays. PLoS Pathog 6, e1001217, https://doi.org/10.1371/journal.ppat.1001217 (2010).

131. Haley, N. J. et al. Detection of chronic wasting disease in the lymph nodes of free-ranging cervids by real-time quaking-induced conversion. J Clin Microbiol 52, 3237-3243, https://doi.org/10.1128/JCM.01258-14 (2014).

132. Henderson, D. M. et al. Quantitative assessment of prion infectivity in tissues and body fluids by real-time quaking-induced conversion. J Gen Virol 96, 210-219, https://doi.org/10.1099/vir.0.069906-0 (2015).

133. Hoover, C. E. et al. Pathways of Prion Spread during Early Chronic Wasting Disease in Deer. J Virol 91, https://doi.org/10.1128/ JVI.00077-17 (2017).

134. Nalls, A. V. et al. Infectious Prions in the Pregnancy Microenvironment of Chronic Wasting Disease-Infected Reeves' Muntjac Deer. J Virol 91, https://doi.org/10.1128/JVI.00501-17 (2017)

135. Hannaoui, S. et al. Destabilizing polymorphism in cervid prion protein hydrophobic core determines prion conformation and conversion efficiency. PLoS Pathog 13, e1006553, https://doi.org/10.1371/journal.ppat.1006553 (2017).

136. Davenport, K. A. et al. PrPC expression and prion seeding activity in the alimentary tract and lymphoid tissue of deer. PLoS One 12, e0183927, https://doi.org/10.1371/journal.pone.0183927 (2017).

137. Manne, S. et al. Ante-mortem detection of chronic wasting disease in recto-anal mucosa-associated lymphoid tissues from elk (Cervus elaphus nelsoni) using real-time quaking-induced conversion (RT-QuIC) assay: A blinded collaborative study. Prion 11, 415-430, https://doi.org/10.1080/19336896.2017.1368936 (2017).

138. Davenport, K. A. et al. Assessment of Chronic Wasting Disease Prion Shedding in Deer Saliva with Occupancy Modeling. J Clin Microbiol 56, https://doi.org/10.1128/JCM.01243-17 (2018).

139. Haley, N. J. et al. Estimating chronic wasting disease susceptibility in cervids using real-time quaking-induced conversion. J Gen Virol 98, 2882-2892, https://doi.org/10.1099/jgv.0.000952 (2017).

140. Haley, N. J. et al. Chronic wasting disease management in ranched elk using rectal biopsy testing. Prion 12, 93-108, https://doi.or g/10.1080/19336896.2018.1436925 (2018).

141. Moore, S. J. et al. Pathologic and biochemical characterization of $\operatorname{PrP}(\mathrm{Sc})$ from elk with PRNP polymorphisms at codon 132 after experimental infection with the chronic wasting disease agent. BMC Vet Res 14, 80, https://doi.org/10.1186/s12917-018-1400-9 (2018).

142. McNulty, E. et al. Comparison of conventional, amplification and bio-assay detection methods for a chronic wasting disease inoculum pool. PLoS One 14, e0216621, https://doi.org/10.1371/journal.pone.0216621 (2019).

143. Cooper, S. K. et al. Detection of CWD in cervids by RT-QuIC assay of third eyelids. PLoS One 14, e0221654, https://doi. org/10.1371/journal.pone.0221654 (2019).

\section{Acknowledgements}

The authors wish to thank Luigi Celauro (SISSA) for technical support in RT-QuIC substrates preparation and Rebecca Davidson (Norwegian Veterinary Institute) for critical review of the manuscript. This study was supported in part by the Italian Ministry of Health (GR-2013-02355724 and RC) and Associazione Italiana Encefalopatie da Prioni (A.I.En.P.) to FM and by the Norwegian Directorate of Agriculture (Reindeer Husbandry Development Fund) project 17/20695-11 to SLB.

\section{Author contributions}

E.B., T.T.V., S.L.B. and F.M. designed the experiments and E.B., T.T.V., L.T. and F.A.C. performed the practical work. G.S. produced the recombinant proteins. E.B., T.T.V., S.L.B. and F.M. wrote the manuscript and E.B., T.T.V., G.L., G.G., S.L.B. and F.M. critically revised it. All the authors read and approved the final manuscript.

\section{Competing interests}

The authors declare no competing interests.

\section{Additional information}

Supplementary information is available for this paper at https://doi.org/10.1038/s41598-019-55078-x.

Correspondence and requests for materials should be addressed to F.M.

Reprints and permissions information is available at www.nature.com/reprints.

Publisher's note Springer Nature remains neutral with regard to jurisdictional claims in published maps and institutional affiliations. 
(c) (i) Open Access This article is licensed under a Creative Commons Attribution 4.0 International License, which permits use, sharing, adaptation, distribution and reproduction in any medium or format, as long as you give appropriate credit to the original author(s) and the source, provide a link to the Creative Commons license, and indicate if changes were made. The images or other third party material in this article are included in the article's Creative Commons license, unless indicated otherwise in a credit line to the material. If material is not included in the article's Creative Commons license and your intended use is not permitted by statutory regulation or exceeds the permitted use, you will need to obtain permission directly from the copyright holder. To view a copy of this license, visit http://creativecommons.org/licenses/by/4.0/.

(C) The Author(s) 2019 